\title{
FORMAÇÃO CONTINUADA E CONDIÇÕES DE TRABALHO: UMA ANÁLISE SOBRE OS PROFESSORES QUE ATUAM EM CRECHES
}

\author{
CONTINUED FORMATION AND WORKING CONDITIONS: ANALYSIS ABOUT \\ TEACHERS WHO WORK IN NURSERY CENTER.
}

\section{FORMACIÓN CONTINUADA Y CONDICIONES DE TRABAJO: UNA ANÁLISIS ACERCA DE LOS PROFESORES QUE ACTUAN EN GUARDERÍA}

\author{
Naiara Caroline Vaz Rosa-Pereira \\ Universidade Estadual Paulista "Júlio de Mesquita Filho" (UNESP) Faculdade de Ciências e \\ Letras (FCLAR) Mestre em Educação Escolar, especialista em Educação e Sociedade, \\ especialista em Docência no Ensino Superior. Área de pesquisa: Educação Infantil com ênfase \\ na formação de professores, valorização profissional e condições de trabalho dos professores. \\ E-mail: naiara_rosapereira@yahoo.com.br
}

\section{RESUMO}

O presente artigo discute os desdobramentos acerca da formação inicial e continuada dos professores que atuam em creches mediante o contexto de desvalorização da Educação Infantil em nosso país. Pretende-se compreender se é possível encontrar condições de trabalho que viabilizem a formação continuada destes profissionais partindo do pressuposto de que estas são de extrema importância quando pensamos o desenvolvimento profissional, o aprimoramento do trabalho docente e a qualidade do atendimento pedagógico. Ancorando-nos na abordagem qualitativa, os dados os quais subsidiam nossas análises referem-se a coleta realizada para o desenvolvimento de dissertação. Foram aplicados questionários mistos a 27 professoras de creche com sede em 9 unidades de diferentes localizações. A partir do estudo é possível afirmar que as condições de trabalho são determinantes e capazes de viabilizar ou não a busca por formações continuadas e quando deterioradas, se tornam um empecilho no caminho do desenvolvimento profissional docente.

Palavras-chave: Formação Continuada. Creche. Condições de trabalho.

\begin{abstract}
This present article discusses the outspreading about the initial and continued formation of teachers who work in nursery center in connection with the context of devaluation of Child Education in our country. It is the intention to understand if it is possible to find out working conditions that are feasible the continued formation of those professional from the presupposed that those are of maximum importance when we think about the professional development, the improvement of teaching work and the quality of pedagogical assistance. When being connected in a qualitative approach, the data which subsidize our analyses refer to the collection which was made to the development of the dissertation. Questionnaires were applied to 27 daycare teachers in nine schools from different locations. From that study is possible to confirm that the work conditions are determined and able to make feasible or not the search for continued formation and when they are spoilt, they become an obstacle in the way of teaching professional development.
\end{abstract}

Keywords: Continued Formation. Nursery Center. Working Conditons. 


\section{RESUMEN}

El presente artículo discute los desdoblamientos acerca de la formación inicial y continuada de los profesores que actúan en guarderías mediante el contexto de devaluación de la Educación Infantil en nuestro país. Se pretende comprender si es posible encontrar condiciones de trabajo que viabilicen la formación continuada de estos profesionales partiendo del supuesto de que éstas son de extrema importancia cuando pensamos el desarrollo profesional, el perfeccionamiento del trabajo docente y la calidad de la atención pedagógica. En base al enfoque cualitativo, los datos que subsidian nuestros análisis se refieren a la recolección realizada para el desarrollo de disertación de maestría. Se aplicaron cuestionarios mixtos a 27 profesoras de guardería con sede en 9 unidades de diferentes ubicaciones. A partir del estudio es posible afirmar que las condiciones de trabajo son determinantes y capaces de viabilizar o no la búsqueda por formaciones continuadas y cuando deterioradas, se convierten en un obstáculo en el camino del desarrollo profesional docente.

Palabras clave: Formación Continua. Guardería. Condiciones de Trabajo.

\section{INTRODUÇÃO}

Através da Constituição Federal de 1988, a Educação Infantil passou a ser reconhecida como atendimento educacional, dever do estado e direito de todas as crianças, assim, inserida no capítulo da Educação, fundamentou uma mudança de paradigma social a respeito do atendimento à criança. Destacamos este fato como um marco no respeito e valorização da educação das crianças pequenas em nosso país, pois desta maneira, a criança passou a ser entendida como ser de direitos e reconhecida como cidadã, fato este que desencadearia a apropriação de uma concepção de criança explicitada posteriormente pelos documentos legais. Contudo, somente com a aprovação da Lei de Diretrizes e Bases da Educação Nacional (LDBEN) no 9394 em 1996, a Educação Infantil ampliou seu reconhecimento social, sendo incluída como primeira etapa da Educação Básica de nosso país, a qual abrange hoje a faixa etária dos 0 aos 5 anos.

Diante esses marcos legais e sob os movimentos de reconhecimento da criança como um sujeito de direitos, reflexões sobre elas passam a se aprofundar, especialmente sobre a organização e pressupostos de sua educação. Se apresenta na letra da Lei, uma concepção pedagógico/educacional de atendimento à criança e não mais de um atendimento com vieses à assistência social como podemos analisar através das pesquisas de Kishimoto (1988; 2002), Kuhlmann (2001; 2007) e Duarte (2012).

Analisando as discussões legais, outros documentos foram criados especificamente para esta etapa educacional, estimulando reflexões sobre diversos aspectos de sua constituição, o que representou um grande salto no que se refere a valorização da Educação Infantil e o respeito pela infância. Uma concepção de criança inserida no mundo enquanto protagonista de seus 
direitos se revela e um novo olhar se volta ou deveria se voltar a ela. Mesmo diante desses avanços é importante salientar que podemos encontrar infindáveis entraves em seu caminho, assim, a Educação infantil têm sido pauta de muitas pesquisas que tratam e discutem seus avanços e retrocessos em contexto nacional, dentre elas destacamos as de Angotti (2006; 2009), Corrêa (2003; 2011a, 2011b), Faria e Angotti (2014) e Serrão (2012).

Destacamos e discutiremos um ponto em especial que reflete o percurso turbulento de valorização da Educação Infantil em nosso país e que influenciou a escolha de nosso contexto de pesquisa: a creche. No ano de 2009, a partir Ementa Constitucional n ${ }^{\circ}$ 59, as crianças da préescola (4-5 anos), passaram juntamente com o Ensino Fundamental e Médio, a integrar o quadro da obrigatoriedade da educação brasileira, sendo incluídas no direito público subjetivo à educação. O direito público subjetivo torna obrigatória e gratuita a oferta e matrícula de crianças e adolescentes entre 4 e 17 anos de idade.

Ao analisar este fato, é possível notar a nítida separação da primeira etapa educacional entre 0-3/4-5, o que representa a expressão da desvalorização do atendimento educacional das crianças na faixa etária da creche. Esta separação interfere em questões de destinação de verbas e financiamento da educação, pois deixa o segmento 0-3 em segundo plano na distribuição de recursos. Este fato pode ser constatado pela redação da própria ementa em seu artigo 3 "§ 3으 A distribuição dos recursos públicos assegurará prioridade ao atendimento das necessidades do ensino obrigatório, no que se refere a universalização, garantia de padrão de qualidade e equidade, nos termos do plano nacional de educação".

Diante disso, é possível considerar que o poder público nitidamente fragmenta a primeira etapa educacional de nosso país e compromete o direito à educação de qualidade garantido em lei a essas crianças (BARROS; ROSA, 2016). Algumas pesquisas nos mostram a distinção do governo, que de certa maneira valoriza a pré-escola em detrimento da creche, o que marca um enfraquecimento aos ganhos que a Educação Infantil havia alcançado em período recente posterior à Constituição de 1988. É possível constatar que mesmo a partir dos avanços na letra da Lei e no discurso de uma Educação Infantil de qualidade, as políticas públicas destinadas a ela ainda são insuficientes (FARIA; ANGOTTI, 2014; CORRÊA, 2011).

Sendo o atendimento educacional nas creches desvalorizado e deixado em último plano pelo poder público, essa desvalorização recai sobre o professor que nela atua, seu reconhecimento social e profissional fica comprometido, implicando em seu desprestígio, fazendo com que a sociedade o considere por muitas vezes um mero cuidador de crianças destituído de profissionalidade. É importante salientar, que o pouco comprometimento do poder público para com a Educação Infantil, implica diretamente na concepção social que lhe é dada 
e acaba por reafirmar a conotação simplista e assistencial com qual a sociedade a têm tratado ao longo dos anos, prejudicando assim a profissionalização do professor que atua nesta etapa, em especial aos que trabalham nas creches com as crianças de 0-3 anos. Em consequência disto, vemos baixíssimos salários e precárias condições de trabalho o que desencadeia notada frustração profissional e incidi sobre o desenvolvimento do trabalho docente.

Nóvoa (1995) define o conceito de profissionalização como sendo um processo pelo qual os trabalhadores melhoram sua renda, seu estatuto e podem aumentar sua autonomia. Desta maneira, a profissionalização está vinculada a valorização e reconhecimento profissional destes professores e ainda às políticas públicas educacionais.

Diante destas questões e das pesquisas sobre a desvalorização da Educação Infantil e de seus professores é que se estrutura a análise do presente artigo. Os dados que aqui serão analisados são fruto da coleta feita para a dissertação intitulada "A valorização profissional docente no município de Ribeirão Preto: um estudo sobre creches" (ROSA-PEREIRA, 2017) Para tal, foram aplicados questionários mistos à 27 professoras da rede municipal de ensino atuantes nos Centros de Educação Infantil (faixa etária creche) com o objetivo de compreender aspectos de suas condições de trabalho que foram modificadas mediante algumas alterações legais em seu estatuto. A pesquisa de Rosa-Pereira (2017) discute vários aspectos acerca das condições de trabalho de professores de creche de um município situado no interior de São Paulo, e o presente artigo desdobra-se sobre um dos aspectos emergentes dos dados analisados: Existem condições de trabalho que viabilizem a formação continuada de professores que atuam nas creches?

\section{DESENVOLVIMENTO}

\subsection{A formação inicial}

Alguns documentos produzidos em esfera nacional revelam uma aparente preocupação com aspectos da qualidade na Educação Infantil, dentre eles destacamos o Referencial Curricular Nacional para Educação Infantil (RCNEI) de 1998, as Diretrizes Curriculares para Educação Infantil (DCNEI) de 1999, os Parâmetros Nacionais de qualidade para Educação Infantil de 2006 e os Indicadores de qualidade na Educação Infantil de 2009. Este fato pode ser considerado um passo adiante na luta em prol de seu reconhecimento e valorização, contudo, isso não garante que a letra da lei seja efetivada, em especial quando há negligência por parte 
do poder público. Em relação a qualidade do atendimento educacional, diversos aspectos podem ser discutidos, destacamos aqui a formação de professores.

A LDBEN de 1996 determinou que a partir de 2007 só seriam admitidos nos sistemas de ensino professores formados em nível superior, contudo em redação dada pela lei $\mathrm{n}^{\circ} 13.415$ de 2017 em seu artigo 62 podemos encontrar a seguinte citação:

Art. 62. A formação de docentes para atuar na educação básica far-se-á em nível superior, em curso de licenciatura plena, admitida, como formação mínima para o exercício do magistério na educação infantil e nos cinco primeiros anos do ensino fundamental, a oferecida em nível médio, na modalidade normal (BRASIL, 1996).

Assim, embora a lei recomende a formação de professores em nível superior, o curso de Magistério, de nível médio, ainda é aceito na Educação infantil e nos anos iniciais do Ensino Fundamental. Analisando alguns dados estatísticos sobre a escolarização dos professores da Educação Infantil, podemos observar que a nível nacional 60,8\% dos professores que atuam em instituições de Educação Infantil possuem formação superior. No estado de São Paulo, este número passa a $76 \%$ e especificamente no município estudado pela pesquisa, o número de professores atuando na Educação Infantil com formação em nível superior chega a 77,4\% (BARROS, 2015).

Contudo, a realidade de nosso país é bastante diversa e é possível observar ao analisar editais de concursos que no intuito de preencher seus quadros de educadores, diversas secretarias aceitam inscrições nos concursos daqueles que não têm como formação inicial cursos superiores. Formação inicial, explicita-se aqui, como a formação a qual inseriu estas profissionais nas atribuições docentes, ou seja, a formação que lhes propiciou o ingresso no cargo.

A partir dos dados que emergiram neste estudo, é possível observar que o percentual fica um pouco abaixo da média apresentada pela pesquisa de Barros (2015), pois apenas dezoito de um total de vinte e sete das professoras pesquisadas possuem nível superior, isto é, 66,6\%. Essa discrepância pode estar vinculada ao fato de que em nossa pesquisa analisamos apenas professores do segmento creche, faixa etária onde podemos encontrar professores com a menor escolarização dentre as etapas educacionais. No que se refere a formação inicial das professoras pesquisadas, observamos que nove $(33,3 \%)$ delas possuem apenas magistério, quatro $(14,8 \%)$ curso de Pedagogia e treze $(48,1 \%)$ cursaram magistério e posteriormente Pedagogia. Uma professora possui licenciatura em outra área, tendo cursado Licenciatura em Biologia. 
Através das pesquisas, podemos notar um avanço em relação a formação universitária dos professores que atuam na Educação Infantil, o que necessita ser valorizado por todos os militantes da causa, todos que lutam por uma Educação Infantil de qualidade e pela garantia dos direitos das crianças, contudo, faz-se necessário refletir que estes números representam a certificação destes professores e não a garantia de uma boa formação. Possuir certificação de nível superior infelizmente não garante que elas estejam preparadas para o exercício docente na Educação Infantil. Partindo deste pressuposto, discutiremos como anda a formação em nível superior de professores da Educação Infantil, isto é, dos cursos de licenciatura em Pedagogia.

\subsection{Formação e certificação}

Um dos principais critérios utilizados em escala internacional para avaliar a qualidade de escolas em qualquer nível de ensino têm sido o tipo de formação dos professores que nela atuam. Um dado importante a se destacar, é que quanto mais novas são as crianças atendidas, menor é o nível de formação de seus professores (CAMPOS, FULLGRAF, WIGGERS, 2006).

Que a formação do professor é fator importantíssimo para se pensar em um bom desenvolvimento do trabalho docente é inegável e a partir de agora a discutiremos mais profundamente, contudo, é importante destacar que este não é um fator isolado, uma boa formação dos professores não é capaz de realizar por si só um atendimento de qualidade. Condições de trabalho, estruturais e destinação de recursos entre outras coisas se mostram necessárias para efetivação deste direito. Sim, o professor é parte fundamental na busca de um atendimento pedagógico de qualidade que respeite e valorize nossas crianças, contudo, para que ele consiga bem desenvolver seu trabalho é preciso que lhe sejam garantidas condições dignas, o que inclui possibilidade de dar continuidade a sua formação e alcançar seu desenvolvimento profissional. Através de sua formação, o professor deve e ou deveria encontrar os subsídios necessários a uma prática refletida, o professor precisa reconhecer nossos pequenos como protagonistas no processo educacional e mediar as relações respeitando seus direitos fundamentais de expressão.

Assis (2009) afirma que da maneira como foi constituída a Educação Infantil pública de nosso país, atrelada a uma concepção assistencialista, resultou a dicotomia entre cuidar e educar e consequentemente entre profissionais que cuidam (0-3 anos) e que educam (4 e 5 anos). A creche criada a partir da necessidade das famílias na guarda e cuidado das crianças pequenas relaciona seu papel ao cuidado da mulher e assim estruturou suas práticas diante este 
atendimento, muitas vezes sendo visto como substitutas ao papel materno e causando assim uma impressão de que não é importante uma formação específica para tal.

O imaginário popular e até dos meios oficiais pouco afeitos às reflexões sobre a criança e a Educação Infantil referendam, ainda, a perspectiva romântica do século passado, de que para atuar com crianças de 0 a 6 anos basta ser "mocinha, bonita, alegre e que goste de crianças", e a ideia de que não há necessidade de muitas especificações para instalar escolas infantis para os pequenos (KISHIMOTO, 1999, p. 74).

Partindo do pressuposto de que a criança é um sujeito de direitos, faz-se necessário que seja também lembrado o direito que elas têm de que os profissionais que atuam com elas sejam adequadamente formados, pois assim poderão melhor compreender, desenvolver e refletir sobre seu fazer docente. Estes professores precisam estar em contextos que os dignifiquem e os reconheçam como profissionais que são, valorizando seu fazer e possibilitando o seu comprometimento com a educação destas crianças. Diante essa questão é possível indagar: a formação inicial destes professores é capaz de garantir condições para uma significativa realização de seu fazer?

Lima (2014) discute sobre a formação destes professores e se os saberes contemplados por eles seriam suficientes para embasar práticas realmente significativas, a autora relaciona a formação do professor com a qualidade que este pode oferecer as crianças em seu trabalho pedagógico. Através de sua pesquisa, é possível percebermos que os cursos de pedagogia priorizam conteúdos voltados para o ensino fundamental e reserva uma pequena carga horária para as especificidades da Educação Infantil. Essa questão se torna ainda mais delicada quando pensamos o currículo destinado a faixa etária das creches.

A pesquisa de Schultz (2002) aponta a importância da formação do professor para atuação nas creches em cursos de nível superior e a necessidade de um olhar criterioso dos "peritos e legitimadores" os legisladores que tomam as decisões políticas sobre os currículos e cursos para que seus conteúdos sejam capazes de fundamentar as práticas docentes dentro das creches.

Em pesquisa realizada abrangendo 71 cursos de licenciatura presenciais em Pedagogia, distribuídos no Brasil, Gatti (2010) nos apresenta alguns dados interessantes. A autora encontrou 3.513 disciplinas oferecidas por estes cursos, sendo 3.107 obrigatórias e 206 optativas. Deste montante, apenas 5,3\% representam disciplinas relativas a Educação Infantil. Este dado nos mostra que a Educação Infantil não tem sido valorizada nos currículos dos cursos de Pedagogia, o que pode resultar em uma formação defasada ou pouco qualificada. A pesquisa 
demonstra que a abordagem dos cursos de licenciatura em Pedagogia é genérica, não sendo capaz de instrumentalizar teoricamente práticas educativas que sejam suficientemente satisfatórias.

Dialogando com estes dados, a pesquisa de Paulino (2014) nos mostra que a formação por si só não é suficiente para respaldar a prática na Educação Infantil, foram identificadas fragilidades no desenvolvimento profissional do grupo de sujeitos pesquisado. Ao refletir sobre a questão, é necessário considerar, que a certificação não pode ser compreendida como formação, uma formação de qualidade que garanta a esses profissionais se apropriarem de conhecimentos necessários para bem desenvolver sua prática como Freitas (2003) problematiza em sua pesquisa. $\mathrm{O}$ autor considera que a atual política reafirma a desprofissionalização dos professores, sobretudo por meios dos exames de certificação e da ampliação do caráter tutorial da formação de professores.

Flôr (2007) nos traz importantes reflexões ao reiterar que mesmo que tivéssemos uma formação inicial de qualidade isso não seria capaz de proporcionar condições suficientes para uma escola de qualidade e uma boa formação dos docentes pois a sociedade é dinâmica e as transformações sociais podem tornar o adequado de hoje em o não adequado de amanhã. Assim, a autora considera que a formação continuada de professores deve ser vista como alternativa para qualificação de professores e como meio para a constante atualização.

Uma formação consistente é necessária não só para o aprimoramento profissional e sim para a concretização de um direito de todos os professores. Através dela é possível refletir sobre os significados da docência, permear sua prática de significados e fortalecer sua profissionalidade. Neste sentido é necessário que pensemos, é possível considerar alguém formado no dia de sua formatura? (KRAMER, 2011).

\subsection{A formação continuada}

A partir do pressuposto de que a formação dos professores está diretamente relacionada à qualidade de seu trabalho docente, analisar a qualificação dos professores que atuam na Educação Infantil relaciona-se a ideia de busca de investimentos necessários na luta por uma educação de qualidade a nossas crianças, compreendendo que essa formação é fator de referência a qualidade deste atendimento. "A formação do professor é reconhecidamente um dos fatores mais importantes para a promoção de padrões de qualidade adequados na educação, qualquer que seja o grau ou modalidade" (BARRETO, 1994, p.11). 
As pesquisas até aqui analisadas nos apontam que a formação universitária de professores no curso de Pedagogia, por si só, não proporciona elementos suficientes para instrumentalização e embasamento de uma prática significativa, sendo assim, discutiremos um pouco sobre a formação continuada de professores como possível alternativa na busca de complementar a formação inicial. Flôr (2007) nos traz reflexões acerca dos muitos termos que podemos encontrar quando pensamos em formação posterior ao curso superior o que chamamos aqui de formação continuada. Definimos neste trabalho, formação continuada como:

[...] um ato intencional, portanto consciente; voltado à transformação e por isto, que considere o sujeito a ser formado em sua amplitude, ou seja, considera seus conhecimentos, sua história, sua cultura, o meio em que vive, as mudanças e contradições sociais na qual ele vive e trabalha e tem como base o conhecimento (FLÔR, 2007, p. 28).

Muitos autores trazem contribuições importantes para se pensar a formação continuada de professores dentre eles Inforsato e Galindo (2006), Nóvoa (1995), Tardif (2011) e Paulino (2014). Essa formação pode acontecer em serviço, quando oferecida por órgãos ou secretarias de educação, ou ainda em instituições públicas ou privadas de ensino, em cursos de extensão, aperfeiçoamento, pós-graduações e outros.

$\mathrm{Na}$ letra da lei, há um discurso promissor acerca da formação continuada dos professores, especialmente em nossa LDBEN (1996) onde no título VI, encontramos explicitado o direito à formação continuada a todos os profissionais de ensino da educação básica. Ao analisar alguns artigos da lei é possível encontrar pressupostos dessa formação, a atribuição de responsabilidades e questões relativas a destinação de recursos financeiros.

\begin{abstract}
A busca por subsidiar as ações de formação continuada no país acabou projetando preocupações anteriormente nunca vistas em amplitude e contemplação pelos órgãos oficiais de governo. A formação continuada passou de uma atividade esporádica e espontânea das instituições educativas, públicas e particulares, e também do terceiro setor, para uma posição chave no processo de desenvolvimento profissional docente[...] (INFORSATO; GALINDO, 2006, p. 3).
\end{abstract}

A pesquisa de Inforsato e Galindo (2006) afirma que mesmo diante as prerrogativas legais é necessário se refletir sobre como essa formação têm acontecido, em contextos de precarização estrutural, pedagógica e humana alcançar o sucesso é um processo conflituoso. Os autores apontam ainda que historicamente há um confinamento das formações que privilegiam eventos pontuais como cursos, oficinas, seminários, muitas vezes pouco articulados e 
programados, tornando-se incapazes de suprir às necessidades pedagógicas mais imediatas dos professores.

Sendo assim, é preciso que estes programas sejam bem formulados, para que alcance seu objetivo que segundo o documento Referenciais para Formação de Professores (BRASIL, 1999) são: propiciar atualizações, aprofundar as temáticas educacionais, promover processos constantes de autoavaliação e proporcionar condições para construção contínua de competências profissionais apoiando-se na reflexão sobre a prática. É importante salientar que "É por meio da formação continuada que o professor reflete, constantemente, as suas ações educativas na Educação Infantil, a concepção que tem de sua formação, bem como a concepção de criança, de infância, de educação, de professor" (LIMA, 2014, p.9).

Torres (2012) evidência em sua pesquisa que os profissionais da Educação Infantil pouco investem na formação continuada, principalmente em pós-graduações, apenas $10 \%$ do grupo pesquisado possui essa formação. A pesquisa aponta como possível causa a cristalização da ideia de que para a atuar na Educação Infantil é necessário apenas graduação, ou nem isso. Contudo, nossa pesquisa apontou dados um pouco mais satisfatórios, no grupo pesquisado, oito de vinte e sete professoras $(29,6 \%)$ possuem cursos de pós-graduação. Nossa pesquisa considerou como formação continuada, cursos de longa duração, as chamadas especializações, contudo, reconhecemos a importância das demais maneiras de formação continuada no fazer docente, cursos de extensão, aperfeiçoamento, formação em serviço, dentre outras.

Debruçando-nos sobre a questão da continuidade dos estudos dos professores da Educação Infantil, Nascimento (2017) buscou analisar o impacto de um curso de formação continuada, à nível de aperfeiçoamento, nas concepções e práticas pedagógicas dos professores. A partir das análises, foi possível afirmar que o curso provocou mudanças na concepção de criança, Educação Infantil e nas considerações sobre o papel do professor, contribuindo assim para significativas modificações e reflexões sobre a prática pedagógica dos mesmos. As participantes da pesquisa afirmaram que as contribuições do curso proporcionaram condições de realizar um trabalho pedagógico mais consistente, repensar os limites de sua prática e seus desdobramentos na educação das crianças.

Enquanto elemento ativo na formação do outro, o professor de educação infantil necessita de uma formação que o ajude a compreender não só a importância de sua atividade, mas as consequências dessas em sua formação e na formação das crianças que educa. Para que a formação continuada de professores avance é preciso a superação das concepções preparatória e romântica que ainda permeiam e se consolidam no contexto da educação infantil (NASCIMENTO, 2017, p. 52). 
Refletindo sobre a postura e posicionamento dos professores da Educação Infantil, Angotti (2007), salienta que é necessário que o professor avive em si o compromisso de uma constante busca do conhecimento como alimento para o seu crescimento pessoal e profissional, pois assim, ele poderá sentir segurança e confiabilidade na realização de seu trabalho docente. "Esta busca poderá instrumentalizá-lo para assumir seus créditos, seus ideais, suas verdades, contribuindo para referendar um corpo teórico que dê sustentação para a realização de seu fazer" (p.64).

Diante este contexto onde a formação continuada se mostra muito importante para o aprimoramento do trabalho docente e desenvolvimento profissional, o que estaria os desestimulando? Os dados nos mostram que poucos professores da Educação Infantil as têm procurado, assim, nos indagamos: por que estes professores não estão buscando por sua formação continuada?

\subsection{As condições de trabalho}

É evidente a intranquilidade dos docentes mediante o descaso com a educação em contexto nacional, é possível encontrarmos um quadro díspar e problemático em relação a produção e implementação de políticas educacionais comprometidas e de formação e valorização dos professores da Educação Básica (DURLI; NARDI; SCHNEIDER, 2011). A Educação Básica de nosso país, a qual inclui atualmente três etapas - Educação Infantil, Ensino Fundamental e Ensino Médio - não pode ser vista como unidade no que tange a profissionalização, remuneração e condições de trabalho de seus professores. "Falar da condição de professoras da educação básica não é a mesma coisa que falar da condição de "professoras" de creche, mesmo que atuando em creche estejam atuando na educação básica" (MONTEIRO, 2007, p.13). Como vimos em pesquisas já referenciadas neste trabalho, a Educação Infantil têm sido menosprezada pelo poder público de nosso país.

Este estudo relaciona uma estreita ligação entre as condições de trabalho dos professores de creche e a busca por sua formação continuada, reconhecendo que estas condições são parte fundamental para viabilizar o acesso a essa formação. No contexto atual a escola está submetida a precárias condições, consequentemente, os professores têm sofrido dificuldades enormes devido à insuficiência de recursos. Salários baixíssimos, a desvalorização social da profissão e condições de trabalho precárias fazem parte do panorama nacional (ALMEIDA, 2002).

Nascimento e Santos (2015) definem condições de trabalho docente: 
Em síntese, consideramos que as condições de trabalho docente compreendem todos os recursos que tornam possível a realização da atividade de ser professor - sejam eles de ordem estrutural, operacional, pedagógica, financeira, material, humana e situam-se em um período histórico dado (p. 6).

Assim, é possível compreender, que as condições de trabalho dos professores pressupõem investimentos e comprometimento por parte do poder público, e que são capazes de interferir no fazer docente, tornando-se um fator facilitador ou prejudicando seu desenvolvimento. Como explicitado anteriormente, os dados que aqui serão apresentados emergiram da coleta feita para dissertação de mestrado Rosa-Pereira (2017). Mediante mudanças legais que garantiram melhores condições de trabalho a professoras de creche do município pesquisado, questões acerca da viabilização a essas professoras de inserir-se em um movimento de busca por sua formação continuada emergiram.

As mudanças foram implementadas pelo Estatuto Público Municipal e propiciou alterações em aspectos significativos das condições concretas de trabalho, tais como: redução da carga horaria, aumento salarial, remuneração de hora-atividades destinadas a planejamentos, plano de carreira, isonomia de direitos em relação aos demais docentes e mudança de nomenclatura (de educadores de creche para professores da educação básica I). Estas mudanças mostraram-se capazes de interferir no desenvolvimento do trabalho docente, otimizando-o significativamente. Do total de professoras pesquisadas (vinte e sete), vinte e seis afirmam ter atualmente, melhores condições de desenvolvê-lo (ROSA-PEREIRA, 2017).

Vieira e Oliveira (2013) ao pesquisar sobre as condições de trabalho dos professores da Educação Infantil puderam encontrar dois processos presentes, a precarização e a intensificação, o que também foi apontado pela pesquisa de Pinto (2009). A precarização consiste nas atribuições de funções e tarefas simultaneamente sem que sejam oferecidas condições para realização das mesmas, pode também ser entendida como o emprego de pessoas sem formação adequada para substituir professores em seu trabalho pedagógico.

Portanto, podemos perceber que a precarização do trabalho do docente se dá frente às relações de trabalho cada vez mais frágeis, nas quais os professores perdem seus direitos trabalhistas e há uma desvalorização salarial cada vez mais significativa. Esse contexto colabora para a intensificação do trabalho docente, pois ganhando mal os professores são obrigados a trabalharem em mais de um lugar, de modo que dupla ou tripla jornada caracteriza a rotatividade e a itinerância. Deste modo, o tempo disponível dos professores para planejar e pensar sobre o seu trabalho fica comprometido (ALVARENGA, 2009, p. 47). 
Ferraz (2008) pondera que a precarização não é expressa somente na exploração física do trabalhador e sim perpassa a sua subjetividade quando trata da retirada de seus direitos, essa questão nos leva a refletir as precárias condições de trabalho dos professores da Educação Infantil encontradas em nosso país, e também sobre os muitos direitos destes profissionais garantidos em lei que não encontram subsídios para sua efetivação.

O conceito de intensificação também identificado pelos autores diz respeito à imposição de sobrecarga de trabalho, seja por necessidade de realização de atividades extras ou em decorrência da baixa remuneração que quase sempre exige complementação salarial por meio de outras ocupações (VIEIRA; OLIVEIRA, 2013). É possível afirmar que muitos professores são levados a buscar formas complementares de renda em decorrência de seus baixos salários o que acarreta em um excessivo cansaço e sobrecarga. A pesquisa de Alvarenga (2009) reafirma essa posição e considera que além das condições precarizadas, o trabalho docente enfrenta um processo de intensificação, processo este refletido pela sobrecarga de trabalho aliada a pressões e cobranças quanto a realização de suas atividades. "A desvalorização salarial contribui para que, muitas vezes, os docentes sejam obrigados a trabalhar em várias escolas, comprometendo a qualidade de seu trabalho [...]" (ALVARENGA, 2009, p.39).

Bertonceli e Martins (2016) consideram que a intensificação no trabalho docente manifesta-se na exploração de tempo dos professores que não trabalham exclusivamente dentro das escolas, o que acarreta em exaustão e consequentemente em prejuízo de seu trabalho docente.

O processo de intensificação acontece também fora do ambiente escolar, quando os professores se comprometem com muitas atividades que a rotina docente demanda. Muitas vezes os professores se responsabilizam pelos resultados de seu trabalho e se cobram para que "deem conta de tudo" (OLIVEIRA E VIEIRA, 2012). Desta maneira, seu tempo fica comprometido, tempo este que poderia ser melhor utilizado se fosse ocupado com sua formação continuada, pois a busca da qualidade de seu trabalho deve considerar um conjunto de ações. Apple (1995) incide sobre o processo de intensificação as várias formas pelas quais o trabalho do professor pode ser prejudicado, desde não ter tempo para tarefas triviais como ir ao banheiro, até a falta de tempo para se atualizar em sua área e seu trabalho.

É necessário salientar a importância de que os professores de creche tenham condições de realizar suas atividades docentes em momentos destinados para tal e que façam parte de sua carga horária de trabalho, sendo assim remunerados, que recebam salários que lhe permitam ter tempo hábil para investir em sua formação continuada e não necessitem buscar outras formas 
de renda como complementação, evitando assim seu desgaste, cansaço excessivo, sua estagnação e consequentemente o prejuízo a seu trabalho docente.

A partir das mudanças ocorridas no município pesquisado, as professoras demonstram vontade de ir em busca de sua formação continuada, o que nos permite inferir que elas reconhecem a importância deste movimento para seu desenvolvimento profissional. Dezoito das vinte e sete professoras, em questão dissertativa, apontaram a possibilidade de buscar conhecimento como fruto benéfico da otimização das condições concretas de trabalho, em especial a redução da carga horária com aluno, que através da mudança legal passou do regime integral para parcial no município pesquisado. A possibilidade de realização de cursos é destacada por seis professoras e este dado vincula-se especialmente a melhoria das condições de trabalho tais como o aumento de salário e mais tempo disponível em decorrência da carga horária reduzida.

Kramer (1994) já discutia a importância das condições de trabalho na Educação Infantil para que estes profissionais tivessem condições e tempo para estudar e se qualificarem. Os dados de nossa pesquisa mostram que com as devidas condições, as professoras se sentem motivadas a buscar investimentos a seu trabalho docente. "Com a mudança consegui fazer alguns cursos de aperfeiçoamento, pois sobrou mais tempo para me dedicar ao estudo" (Professora 5), tempo foi um fator muito declarado pelas professoras como facilitador na busca de sua formação continuada "Temos mais tempo para realizar pesquisas e buscar novos conhecimentos preparando atividades diversificadas" (Professora, 18).

A declaração da professora 6 diz "Sobrou mais tempo para estudar", o que complementa a afirmação da professora 19 que declara que com mais tempo livre têm oportunidade de fazer cursos de aperfeiçoamento. O termo específico formação continuada aparece na declaração da professora 20 quando ela declara que a partir da melhoria das condições de trabalho buscou por sua qualificação "Tenho feito cursos de formação continuada".

A pesquisa de Amorin, Lima e Araújo (2017) buscou analisar o perfil de professores que atuam na Educação Infantil, os autores analisaram aspectos da formação inicial e continuada de 26 professores, entre especialistas e regentes de sala e puderam constatar que a carga horária trabalho, dentre outros motivos, torna a formação continuada do grupo dificultosa.

Relacionado também a carga horária de trabalho está o sentimento de cansaço, o desgaste físico e psicológico dos professores. Professores extremamente cansados consequentemente não terão ânimo, tampouco motivação, para inserir-se num contexto de formação continuada. A partir de nossa pesquisa é possível afirmar uma significativa melhora 
nos níveis de cansaço físico e psicológico dos professores após as melhorias suscitadas pela mudança legal, isto é, a partir da melhora das condições de trabalho, este condicionante também foi significativamente melhorado.

Um fator que emergiu significativamente como determinante no contexto das condições concretas de trabalho do grupo pesquisado foi o aumento salarial alcançado. A partir das mudanças legais as professoras de creche passaram a receber salários condizentes com os demais professores o que foi apontado por elas como um fator importante para sua formação continuada. "Com um ordenado melhor pude investir mais em cursos e materiais de apoio [...]" (Professora 23). A maior possibilidade de compra de materiais didáticos pelas professoras, a partir de melhores salários, foi apontada por três delas. Isso reflete a precariedade das unidades escolares que mediante o contexto de desvalorização não conta com recursos e matérias necessários que instrumentalizem suas práticas. Segundo a pesquisa de Almeida (2002) os professores têm sofrido dificuldades enormes devido a insuficiência de recursos.

Pesquisas como a de Pinto (2009) demonstram que um fator de intensa insatisfação dos professores da Educação Infantil é o seu salário, sendo que $93 \%$ dos sujeitos da pesquisa o consideraram ruim ou regular, apenas $7 \%$ bom e $0 \%$ ótimo. Muitas pesquisas como as de Esteve (1995); Odelios e Ramos (2000) e Sella (2006) nos mostram que a desvalorização dos professores tem ligação direta com sua remuneração.

Os dados analisados em nossa pesquisa mostram que a motivação dos professores está diretamente ligada com suas condições de trabalho, especialmente a sua remuneração, a professora 26 declara "tenho mais vontade e tempo de preparar as atividades", sente-se motivada através da valorização profissional alcançada. Neste sentido, a professora 2 complementa "Eu acho que o professor valorizado e com um salário melhor sempre busca mais conhecimento porque aí temos condições de fazer isso".

\section{CONSIDERAÇÕES FINAIS}

A partir do estudo apresentado e discutido neste artigo, é possível refletir acerca da importância da formação inicial e continuada dos professores que atuam em creches na busca de seu desenvolvimento profissional e da qualidade do atendimento pedagógico oferecido as crianças. Mediante o contexto de desvalorização no qual a Educação Infantil está inserida em nosso país, os desdobramentos da desvalorização da Educação Infantil recaem sobre seus professores implicando em dificuldades de diferentes aspectos, desde sua desvalorização profissional até as péssimas condições de trabalho que lhe são oferecidas. Nesse sentido, o 
objetivo desta pesquisa foi compreender a relevância destas condições de trabalho no movimento de busca destes profissionais por sua formação continuada.

Através do estudo e a partir das declarações das professoras pesquisadas é possível afirmar que as condições de trabalho dos professores que atuam nas creches são determinantes na viabilização ou não da busca por seu aprimoramento profissional através da formação continuada. O grupo pesquisado passou por ganhos significativos em suas condições concretas de trabalho e a partir daí afirmam ter alcançado condições que viabilizaram a busca pelo seu desenvolvimento profissional e consequentemente a otimização de seu trabalho docente.

\section{REFERÊNCIAS}

ALMEIDA, M. I. Profissionalização do professor: problemas e perspectivas. In: MENIN, A. M. S.; GOMES, A. A.; LEITE, Y. U. F. (Org.). Políticas públicas: diretrizes e necessidades da educação básica. Presidente Prudente: Ed. FCT/UNESP, p. 21-28, 2002.

ALVARENGA, V. C. A profissionalização do trabalho docente: um estudo das condições de trabalho de professoras de pré-escola. 2009. 168 f. Dissertação (Mestrado em Educação) Universidade Estadual Paulista, Araraquara.

AMORIM, G. C.; LIMA, E. A. de; ARAÚJO, R. de C. T. Formação de professores da Educação Infantil: Reflexões sobre a necessária instrumentalização teórica do profissional atuante com criança com ou sem deficiência. RIAEE - Revista Ibero-Americana de Estudos em Educação, v.12, n.1, p. 387-403, 2017.

ANGOTTI, M. Desafios da Educação Infantil para atingir a condição de direito e de qualidade no atendimento. In: ANGOTTI, M. (Org) Educação Infantil: da condição de direito à condição de qualidade no atendimento. Campinas: Alínea, p. 131- 149, 2009.

Educação Infantil: para que, para quem e por quê? In: ANGOTTI, M. (Org.)

Educação Infantil: para que, para quem e por quê? Campinas: Alínea, p.15-32, 2006.

Espaços de formação docente: os desafios da qualificação cotidiana em instituições de Educação Infantil. In: Nuances: estudos sobre educação. Presidente Prudente: Ed. FCT/UNESP, Ano XIII, v. 14, n. 15 jan./dez. 2007.

Semeando o trabalho docente. In: OLIVEIRA, Z. de M. R. de. Educação Infantil: muitos olhares. 7. ed. São Paulo: Cortez, 2007.

APPLE, M. W. Trabalho docente e textos: economia política das relações de classe e de gênero na educação. Porto Alegre: Artes Médicas, 1995.

ASSIS, M.S.S. Ama, Guardiã, Crecheira, Pajem, Auxiliar: em brusca da Profissionalização do Educador da Educação Infantil. In: ANGOTTI, M. (Org.) Educação Infantil: da condição de direito à condição de qualidade no atendimento. Campinas: Alínea, p. 37-50. 2009. 
BARRETO, A. M. R. F. Por que e para que uma política de formação do profissional de Educação Infantil? p. 11 à 15. In: Por uma política de Formação Profissional de Educação Infantil /MEC/SEF/DPE/COEDI, 1994.

BARROS, B. C. de. Ser professora iniciante na Educação Infantil: aprendizagem e desenvolvimento profissional em contexto de enfrentamento e superação de dilemas. 2015. Dissertação (Mestrado em Educação) - Faculdade de Ciências e Letras, Universidade Estadual Paulista "Júlio de Mesquita Filho", Araraquara, p. 35-42.

BARROS, B.C.; ROSA, N. C. V. Creche e pré-escola: A Educação Infantil fragmentada em direitos e reconhecimento. In: Anais $4^{\text {a }}$ Semana de Formação, Pesquisas e práticas em Educação Infantil: Corpos e Culturas. p.71 à 82, de 12 à 16 de set. São Carlos, UFSCAR, 2016. Disponível em: https://drive.google.com/file/d/0B3inCMpNt_NNaHRlaXM1YkhXd2s/. Acesso em: 23 de fev. de 2018.

BERTONCELI, M.; MARTINS, S. A valorização ou precarização do trabalho docente na Educação Infantil. $10^{\circ}$ Seminário Nacional do HISTEDBR, 18 à 21 de julho, UNICAMP, 2016. Disponível em:

https://www.fe.unicamp.br/eventos/ged/histedbr2016/xhistedbr/paper/viewFile/1080/307. Acesso em: 22 fev. 2018.

BRASIL. Constituição (1988). Constituição da República Federativa do Brasil. Congresso Nacional. Brasília: Senado, 1988.

BRASIL. Ministério da Educação. Lei n. 9.394, de 20 de dezembro de 1996. Estabelece as diretrizes e bases da educação nacional. Lei de Diretrizes e Bases da Educação Nacional, Brasília, DF, 1996.

BRASIL. Ministério de Educação e Cultura. Secretaria de Educação fundamental. Referenciais para formação de Professores. Brasília, 1999.

BRASIL. Referencial curricular nacional para a educação infantil. Brasília: MEC/SEF, 1998.

BRASIL. Indicadores de qualidade na educação infantil. Brasília: MEC/SEB, 2009.

BRASIL. Parâmetros Nacionais de qualidade para a educação infantil. v. 2. Brasília: MEC/SEB, 2006.

BRASIL. Diretrizes Curriculares Nacionais para Educação Infantil. Brasília: CNE/CEB n. 1, 7 abr. 1999.

CAMPOS, M.M.; FULLGRAF, J.; WIGGERS, V. A qualidade da educação infantil brasileira: alguns resultados de pesquisa. Cadernos de Pesquisa, v. 36, n. 127, p. 87-128, jan./abr. 2006.

CORRÊA, B. C. Considerações sobre qualidade na educação infantil. Cadernos de Pesquisa, n. 119 , p. $85-112$, jul. 2003. 
Educação Infantil e Ensino Fundamental: desafios e desencontros na implementação de uma nova política. Educação e Pesquisa, São Paulo, v. 37, 220p. 105-120, jan./abr. 2011a.

Políticas de Educação Infantil no Brasil: ensaio sobre os desafios para a concretização de um direito. Jornal de Políticas Educacionais. Curitiba, n. 9, jan-jun, p. 2029, 2011b. Disponível em: http://www.jpe.ufpr.br/n9.pdf. Acesso em: 15 fev. 2018.

DUARTE, L. F. Desafios e legislações na educação infantil. In: ANPEd SUL, 9., Seminário de Pesquisa em Educação da região Sul. p. 1-12, 2012. Disponível em:

http://www.portalanpedsul.com.br/admin/uploads/2012/GT07_Educacao_e_Infancia/Trabal ho/03_09_17_GT_07_-_Luiza_Franco_Duarte.pdf. Acesso em: 19 out. 2017.

DURLI, Z.; NARDI, E. L.; SCHNEIDER, M. P. Políticas de formação e valorização dos professores da educação básica: (in) consistências das ações e estratégias do par nos municípios. In: REUNIÃO NACIONAL DA ANPEd, 34., Natal, 2011. Disponível em: http://34reuniao.anped.org.br/images/trabalhos/GT05/GT05-185\%20int.pdf. Acesso em: 19 out. 2017.

ESTEVE, J. M. Mudanças sociais e função docente. In NÓVOA, A. (Org.). Profissão Professor. $2^{\text {a }}$ Ed. Porto, Portugal: Porto, 1995.

FARIA, A. de C.; ANGOTTI, M. As diretrizes curriculares nacionais da educação infantil: em busca de um trabalho pedagógico com qualidade. Revista Eletrônica Zero-a-seis. v. 16. n. 3. p. 217-230. Florianópolis, jul./dez 2014.

FREITAS, H. C. L. Certificação Docente e Formação do Educador: regulação e desprofissionalização. Educação e Sociedade, Campinas, vol. 24, n. 85, p. 1095-1124, dezembro, 2003.

FERRAZ, C. L. Trabalho Docente, precarização e a nova hegemonia do capital. In: Universidade e Sociedade, p. 09 à 19, Distrito Federal, nº 41, Jan. 2008.

FLÔR, D. C. Formação continuada de professores na escola: qual o lugar da infância? 2007. 109 f. Dissertação (Mestrado em Educação) Universidade Federal de Santa Catarina Centro de Ciências da Educação. Programa de pós-graduação em Educação. Florianópolis, 2017. Disponível em: https://repositorio.ufsc.br/xmlui/handle/123456789/90389. Acesso em: 23. fev. 2018.

GATTI, B. A. Formação de professores no Brasil: características e problemas. Educação Sociedade, Campinas, v. 31, n. 113, p. 1355-1379, out.-dez.

INFORSATO, E. do C.; GALINDO, C. J. ForMAÇÃO CONTINUADA ERRÁTICA E NECESSIDADES DE FORMAÇÃO DOCENTE: RESULTADOS DE UM LEVANTAMENTO DE DADOS EM MUNICIPIOS PAULISTAS In: REUNIÃO ANUAL DA ANPEd, 29., Caxambu, 2006. Disponível em: http://29reuniao.anped.org.br/trabalhos/trabalho/GT08-2621--Int.pdf. Acesso em: 10 mar. 2018.

KISHIMOTO, T. M. A Pré-escola em São Paulo. São Paulo: Loyola, 1988. 
Política de Formação Profissional para a educação infantil: pedagogia e normal superior. Educação e Sociedade, Campinas, v. 20, n. 68, p.61-79, 1999.

Prefácio. In: CERISARA, A. B. Professores de Educação Infantil: entre o feminino e o profissional. São Paulo: Cortez, 2002.

KRAMER, S. Formação de profissionais de educação infantil: questões e tensões. p. 117 à 132. In: MACHADO, M. L. de A. Encontros e desencontros em Educação Infantil. $4{ }^{\text {a }} \mathrm{ed}$. São Paulo: Cortez, 2011.

O currículo de Educação Infantil e a formação dos Profissionais de Creche e Préescola: Questões teóricas e polêmicas. p.16 à 31. In: Por uma política de Formação Profissional de Educação Infantil /MEC/SEF/DPE/COEDI, 1994.

KUHLMANN JR. M. Educação Infantil e Currículo. In: FARIA, A. L. G.; PALHARES, M. S. (Orgs). Educação Infantil Pós-LDB: Rumos e desafios. 3. ed. Campinas: Autores Associados, 2001.

Mediação, 2007.

Infância e Educação Infantil uma abordagem histórica. 4. ed. Porto Alegre:

LIMA, S. E. A. A formação do professor da educação infantil e o trabalho pedagógico com crianças de 0 a 5 anos de idade. Pergaminho, n. 5. p.1-15, dez. 2014. Centro Universitário de Patos de Minas.

MONTEIRO, T. C. "A gente é muita coisa para uma pessoa só": desvendando identidades de "professoras" de creches. In: REUNIÃO ANUAL DA ANPEd, 30., 2007. Disponível em: http://www.anped.org.br/sites/default/files/gt07-3129-int.pdf. Acesso em: 22 fev. 2016.

NASCIMENTO, F. C. do. Formação continuada de professores da Educação Infantil: a experiência de um curso de formação continuada. 2017. 130 f. Dissertação de Mestrado Universidade Federal do Pará, Instituto de Ciências da Educação. Belém, 2017. Disponível em: http://bdtd.ibict.br/vufind/Record/UFPA_119d8ea0fa7dd9e7c48562553386afc8. Acesso em 23 fev. 2018

NASCIMENTO, M. das G. C. de A.; SANTOS, J. V. As percepções de professoras acerca das condições de trabalho e sua relação com a aprendizagem profissional no início de carreira. In: REUNIÃO NACIONAL DA ANPEd, 37., Florianópolis, 2015. Disponível em: http://www.anped.org.br/sites/default/files/trabalho-gt04-4426.pdf. Acesso em: 31 mar. 2016.

\section{PAULINO, V. B. R. Sentidos que emergem do/circulam no trabalho docente na}

Educação Infantil. 2014. 208 f. Dissertação de Mestrado - Universidade Federal do Espírito Santo - Centro de Educação. Vitória, 2014. Disponível em: http://repositorio.ufes.br/bitstream/10/1153/1/.pdf. Acesso em: 23. fev. 2018.

PINTO, M. de F. N. O trabalho docente na Educação Infantil pública em Belo Horizonte. 2009. 194 f. Dissertação (Mestrado em Educação, Conhecimento e Inclusão Social) Faculdade de Educação da Universidade Federal de Minas Gerais, Belo Horizonte. Disponível em: http://www.bibliotecadigital.ufmg.br/dspace/handle/1843Acesso em: 26 mar. 2016. 
ROSA-PEREIRA, N. C. V. A valorização profissional docente no município de Ribeirão Preto: um estudo sobre creches. 2017. 248 f. Dissertação de Mestrado (Mestrado em Educação Escolar) - Faculdade de Ciências e Letras, Universidade Estadual Paulista "Júlio de Mesquita Filho", Araraquara.

NÓVOA, A. Os professores e a sua formação. Lisboa: Dom Quixote, 1995.

ODELIUS, C. C.; RAMOS, F. Remuneração, renda, poder de compra e sofrimento psíquico do educador. In: AZEVEDO, J. C.; GENTILI, P.; KRUG A., SIMON, C. (Orgs.). Utopia e democracia na educação cidadã. Porto Alegre: Universidade/UFRGS/Secretaria Municipal de Educação, p. 338-354, 2000.

OLIVEIRA, D. A.; VIEIRA, L. F. Condições de trabalho docente: uma análise a partir de dados de sete estados brasileiros. In: OLIVEIRA, D. A.; VIEIRA, F. G. (org). Trabalho na educação básica: a condição em sete estados brasileiros. Belo Horizonte: Fino Traço Editora, p. 153-190, 2012.

SCHULTZ, L. M. J. A criança em situação de berçário e a formação do professor para a educação Infantil. 2002. 240 f. Tese (Doutorado em Educaçaõ). Universidade Estadual Paulista, Faculdade de Filosofia e Ciências. Disponível em:

https://repositorio.unesp.br/handle/11449/101533. Acesso em: 25. fev. 2018.

SELLA, C. A. Retratos de um professor em crise: os docentes em tempos de mudança. 2006. 130 f. Dissertação (Mestrado em Ciências Humanas e Sociais) - Universidade do Oeste de Santa Catarina.

SERRÃO, C. R. B. A política da construção ou da justaposição: a Educação Infantil como $1^{a}$ etapa da Educação Brasileira. In: ANGOTTI, M. (Org.) A Educação Infantil em diálogos. Campinas: Alínea, 2012.

TORRES, G. A. Representação social da Educação Infantil: a percepção dos professores. 2012. 124 f. Dissertação (Mestrado em Psicologia). Centro de Ciências da Saúde Universidade de Fortaleza. Fortaleza. Disponível em:

https://uolp.unifor.br/oul/ObraBdtdSiteTrazer.do?method=trazer\&ns=true\&obraCodigo=9108 8. Acesso em: 25. fev. 2018.

TARDIF, M. Saberes docentes e formação profissional. 12. ed. Petrópolis: Vozes, 2011.

VIEIRA, L. F.; OLIVEIRA, T. G. As condições do trabalho docente na Educação Infantil no Brasil: alguns resultados de pesquisa (2002 -2012). Revista Educação em Questão, Natal, v. 46, n. 32, p. 131-154, mai./ago., 2013. 